\title{
Electron Probe Microanalysis of Uranium Localization in Alpha-Plutonium
}

\author{
A.D. Neuman, T.A. Nothwang, F. G. Hampel, and F. Freibert \\ Materials Science and Technology Division, Los Alamos National Laboratory, MS E574, Los \\ Alamos, NM 87506
}

Plutonium has six allotropic phases. The thermally induced transformations between these phases are typically characterized by thermal hysteresis (up to $50^{\circ} \mathrm{C}$ ) and incomplete phase reversion [1]. By substituting as little as 1 atom of $\mathrm{Ga}$ per 50 atoms of $\mathrm{Pu}$ in the lattice symmetry, allotropic phases such as $\alpha, \beta$, and $\gamma$ allow a higher symmetry phase such as $\delta$ to form. Plutonium as it ages decays into an alpha particle and a uranium atom. Much is known about the alpha particle and its capture of two electrons to form a helium atom and coalescence in formation of helium bubbles; however, little is known of the uranium atom's final disposition.

Figure 1 shows the phase diagram of plutonium and uranium. We propose to study uranium concentrations in new unalloyed alpha plutonium and aged unalloyed alpha plutonium ( 23 yrs. old) by performing electron probe microanalysis (EPMA) and attempt to answer the longstanding question of radiological ingrowth of uranium in plutonium. Figure 2 shows preliminary work indicating the localization of iron in grain boundary triple points. This is where uranium is anticipated to reside. The EPMA analysis involves collecting background corrected element distribution maps of $1280 \times 1280 \mu \mathrm{m}$ areas with a resolution of $256 \times 256$ steps at $5 \mu \mathrm{m}$ intervals with a $5 \mu \mathrm{m}$ beam diameter with a relative precision of 10 percent at an expected concentration level of 0.5 wt. $\%$.

\section{References}

[1] F.J. Freibert, T. Saleh, J.N. Mitchell, P. Crawford, and D.S. Schwartz, "Phases, Microstructures, and Thermodynamic Properties of Ga Alloyed Plutonium," LA-UR-11-00159, presentation, January 2009.

[2] F.H. Ellinger, R.O.Elliot, and E.M. Cramer, J. Nucl. Mater., 1: 235 (1959)

[3] The authors would like to acknowledge Manual Pacheco for his assistance in this work. 


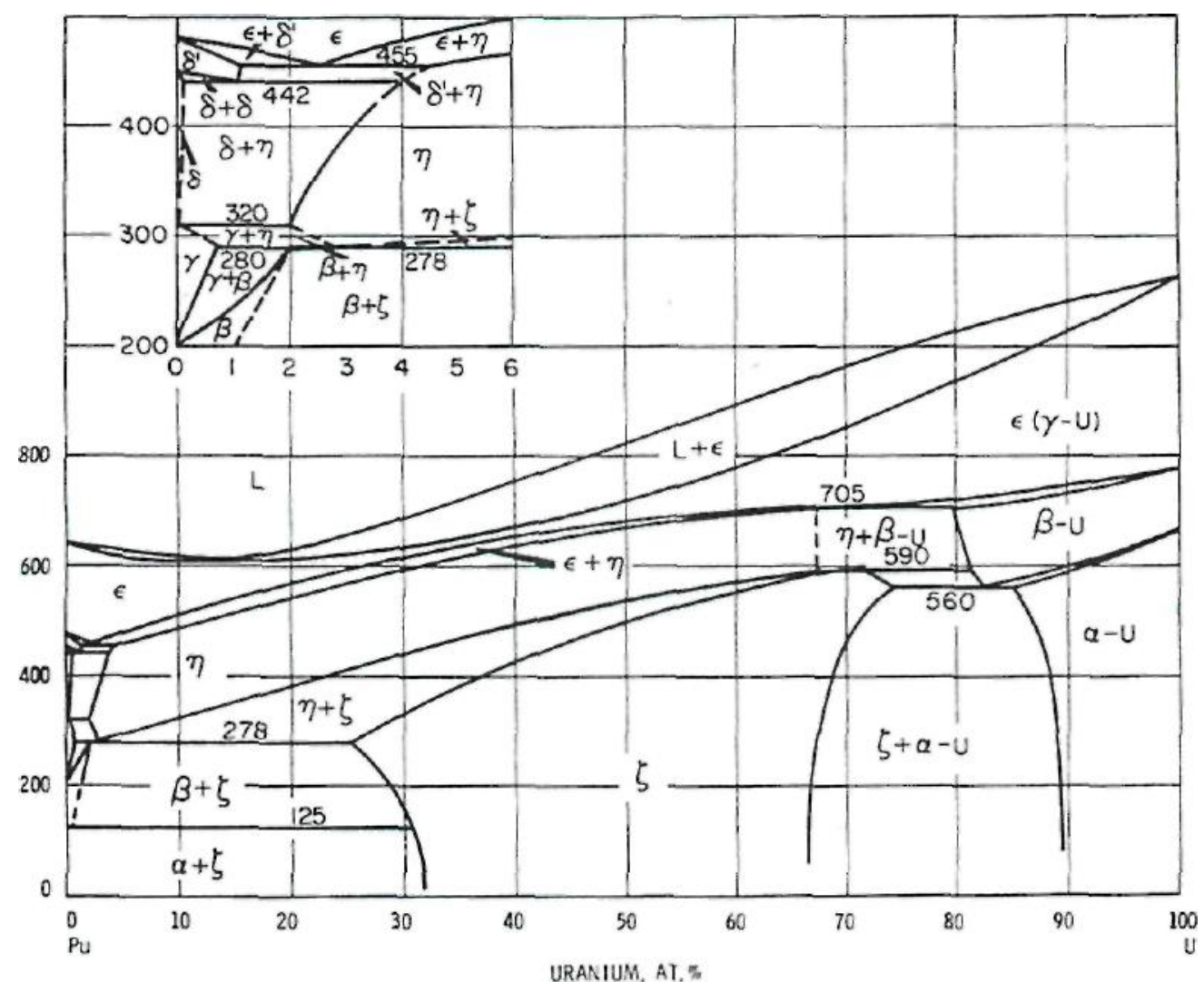

FIG. 1. Plutonium - Uranium phase diagram (Note: y-axis is Temperature ${ }^{\circ} \mathrm{C}$ ) [2]

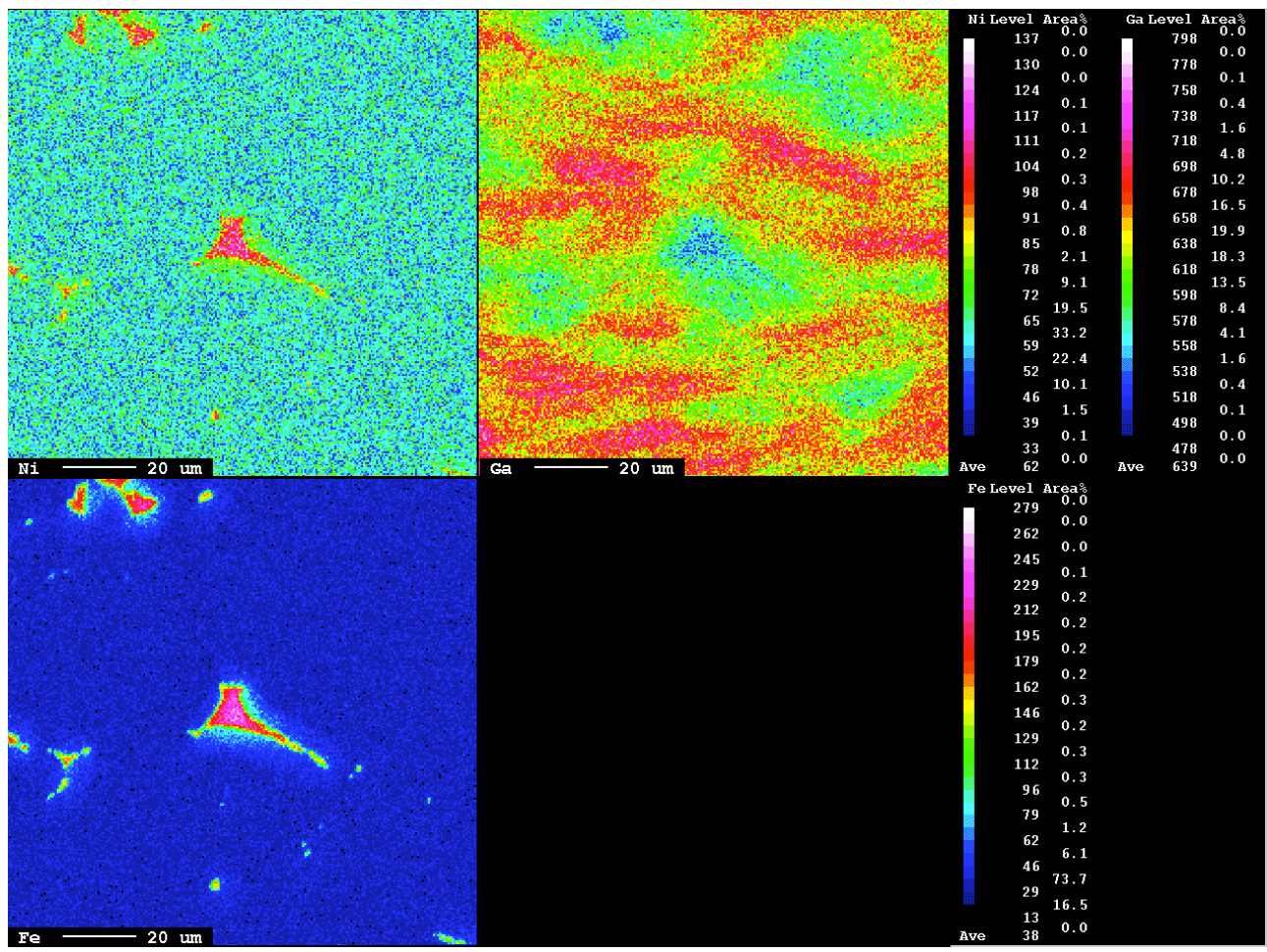

FIG. 2. Elemental maps of a plutonium sample showing the location of nickel, gallium, and iron. 